\title{
Diagnostic and treatment hurdles in plasma cell myeloma with $t(11 ; 14)$ translocation: A case report
}

\author{
SHUN YIN KONG ${ }^{1}$, WING KIT LAM ${ }^{2}$, KA SHU LI $^{1}$, KA PIK YEUNG $^{1}$, CHUNG YIN HA $^{1}$, \\ HO KEI LAI ${ }^{1}$, HAY NUN CHAN ${ }^{1}$, YIU MING YEUNG ${ }^{1}$ and SZE FAI YIP ${ }^{1,2}$ \\ Departments of ${ }^{1}$ Medicine and Geriatrics, and ${ }^{2}$ Pathology, Tuen Mun Hospital, Hong Kong, SAR 999077, P.R. China
}

Received December 22, 2017; Accepted April 17, 2018

DOI: $10.3892 / \mathrm{mco} .2018 .1612$

\begin{abstract}
. $\mathrm{t}(11 ; 14)$ translocation is one of the most common chromosomal abnormalities in plasma cell myeloma. The present case report presented a case of plasma cell myeloma with $\mathrm{t}(11 ; 14)$ translocation, in which the plasma cells were small lymphoplasmacytoids in morphology with positive cluster of differentiation-20 and Cyclin D1 expression. These results led to initial diagnostic difficulties. The patient was refractory to bortezomib-based therapy, and responsive to vincristine, doxorubicin and dexamethasone. However, the prognostic value of $t(11 ; 14)$ in plasma cell myeloma remains to be determined. With recent advances in treatment options, physicians should be aware of the clinical and pathological characteristics of this translocation in plasma cell myeloma.
\end{abstract}

\section{Introduction}

Plasma cell myeloma (PCM) is a neoplastic proliferation of plasma cells producing monoclonal immunoglobulins. $t(11 ; 14)$ translocation is one of the most common chromosomal translocations in PCM (1). In a cohort of 351 PCM patients in the Eastern Cooperative Oncology Group phase III clinical trial E9486, 16\% were detected to have $\mathrm{t}(11 ; 14)(\mathrm{q} 13 ; \mathrm{q} 32)(2)$. The initial diagnostic process may be challenging, and the prognostic significance of $\mathrm{t}(11 ; 14)$ translocation remains debatable. The present clinical case evaluated various characteristics associated with the $\mathrm{t}(11 ; 14)$ translocation.

\section{Case report}

A 40-year old Hong Kong Chinese male patient with a past history of interstitial lung disease, presented in April 2014 with incidental findings of rouleaux on the blood film. Physical examination did not reveal any lymphadenopathy. Serum

Correspondence to: Dr Shun Yin Kong, Department of Medicine and Geriatrics, Tuen Mun Hospital, 23 Tsing Chung Koon Road, Hong Kong, SAR 999077, P.R. China

E-mail: kongshunyin14@gmail.com

Key words: plasma cell myeloma, $\mathrm{t}(11 ; 14)$, cluster of differentiation 20, Cyclin D1 protein electrophoresis indicated $27 \mathrm{~g} / 1$ immunoglobin (Ig) $\mathrm{G}$ paraprotein and the immunoglobulin pattern revealed elevated $\operatorname{IgG}$ at $29.3 \mathrm{~g} / \mathrm{l}$. The $\operatorname{Ig} \mathrm{A}$ and $\operatorname{IgM}$ levels were 1.36 and $0.31 \mathrm{~g} / \mathrm{l}$, respectively. The patients hemoglobin, renal function and calcium levels were normal, and a skeletal survey did not reveal any osteolytic lesions.

The bone marrow aspirate demonstrated $27 \%$ small to medium plasmacytoid cells (Fig. 1) which were positive for cluster of differentiation (CD)138 (Fig. 2A), CD20 (Fig. 2B), CD19, CD38 and CD45, and negative for CD5. They also exhibited strong surface 1 light chain restriction. The initial diagnosis was of involvement of B cell non-Hodgkin lymphoma with extensive plasmacytic differentiation.

Marrow clotting and trephine biopsy, however, did not reveal any obvious lymphoid aggregates, however CD138-positive lymphoplasmacytoid cells were diffusely increased with partial Cyclin D1 expression (Fig. 2C). The final diagnosis was revised to be plasma cell myeloma.

Fluorescent in situ hybridization identified $\mathrm{t}(11 ; 14)$ (q13;q32) (Fig. 3) and no 17p or 13q deletion, 1q amplification, $\mathrm{t}(4 ; 14)$ or $\mathrm{t}(14 ; 16)$. The Myeloid Differentiation Primary Response 88 (MYD88) L265P mutation was not detected.

The patient's myeloma was closely monitored for 2 years and he remained asymptomatic. From February 2017, his paraprotein increased to $68 \mathrm{~g} / \mathrm{l}$ with mild anaemia, despite a normal serum creatinine level. A skeletal survey indicated multiple new osteolytic lesions of the skull. Repeated bone marrow analysis revealed $80 \%$ plasma cells.

The patient was administered two cycles of bortezomib, thalidomide and dexamethasone, however the paraprotein did not improve. Serum creatinine levels also increased to $235 \mu \mathrm{mol} / \mathrm{l}$ in June 2017. Treatment was then altered to bortezomib, cyclophosphamide and prednisolone, however there was no improvement in serum creatinine. Therefore, vincrisitine, doxorubicin and dexamethasone (VAD) treatment was administered. The paraprotein decreased to $38 \mathrm{~g} / \mathrm{l}$ following VAD, however the patient's condition was complicated with pulmonary tuberculosis and Escherichia coli septicemia with multi-organ failure, despite intensive care.

\section{Discussion}

PCM with $\mathrm{t}(11 ; 14)(\mathrm{q} 13 ; \mathrm{q} 32)$ is associated with lymphoplasmacytoid morphology, and $\sim 80 \%$ of PCM cases with $\mathrm{t}(11 ; 14)$ 


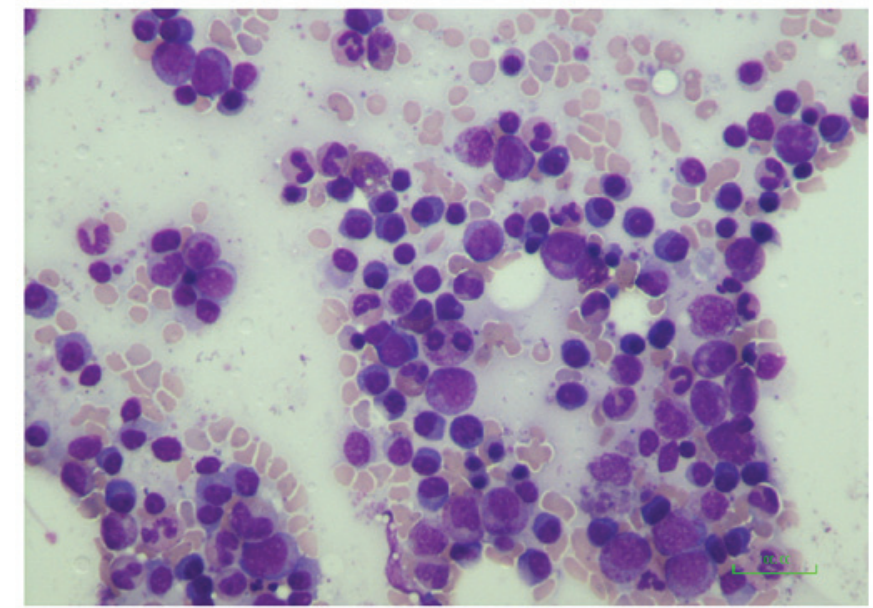

Figure 1. Bone marrow aspirate revealing a number of abnormal plasmacytoid cells, which accounted for $27 \%$ of nucleated cells. (May-Grünwald; magnification, $\mathrm{x} 400$ )
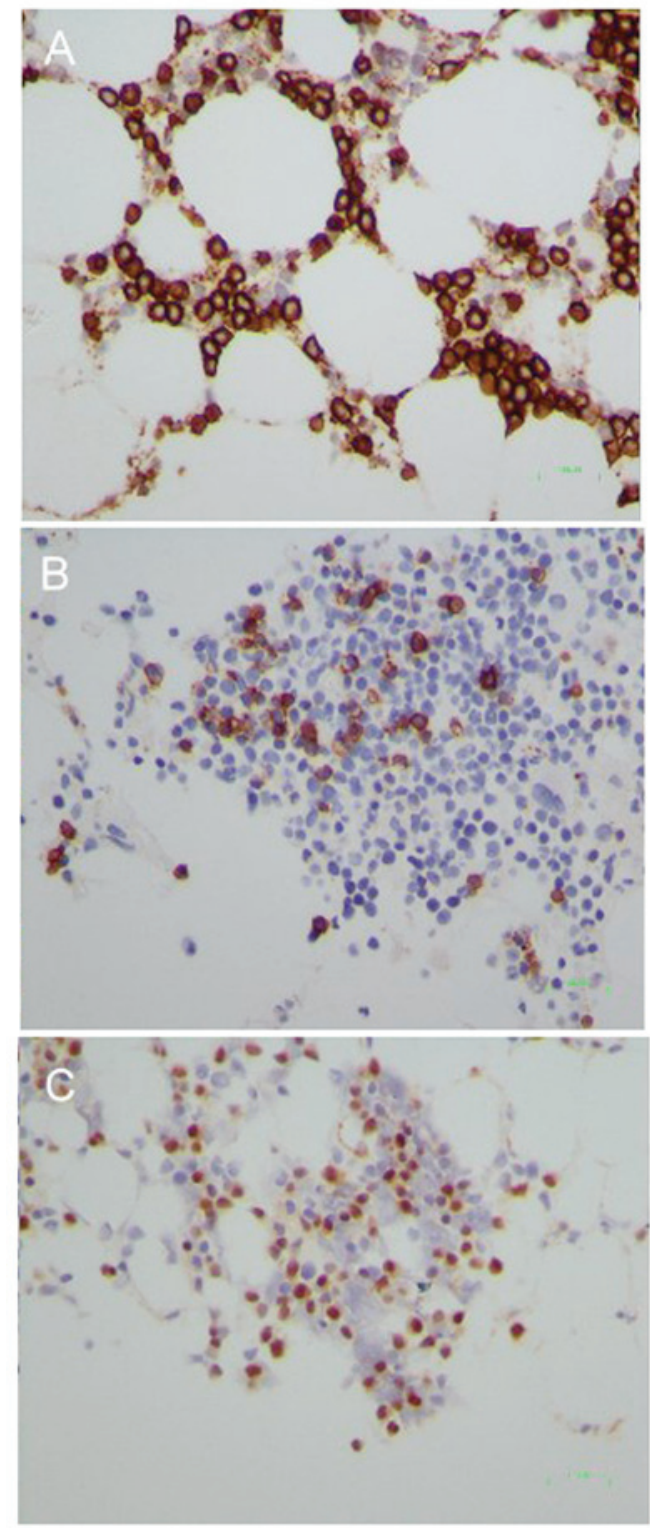

Figure 2. Following immunohistochemistry, the plasmacytoid cells were observed to be (A) CD138+ (magnification, $\mathrm{x} 400$ ), (B) CD20 ${ }^{+}$(magnification, $\mathrm{x} 200)$ and $(\mathrm{C}) \mathrm{CyclinD}^{+}$(magnification, $\left.\mathrm{x} 200\right)$. CD, cluster of differentiation

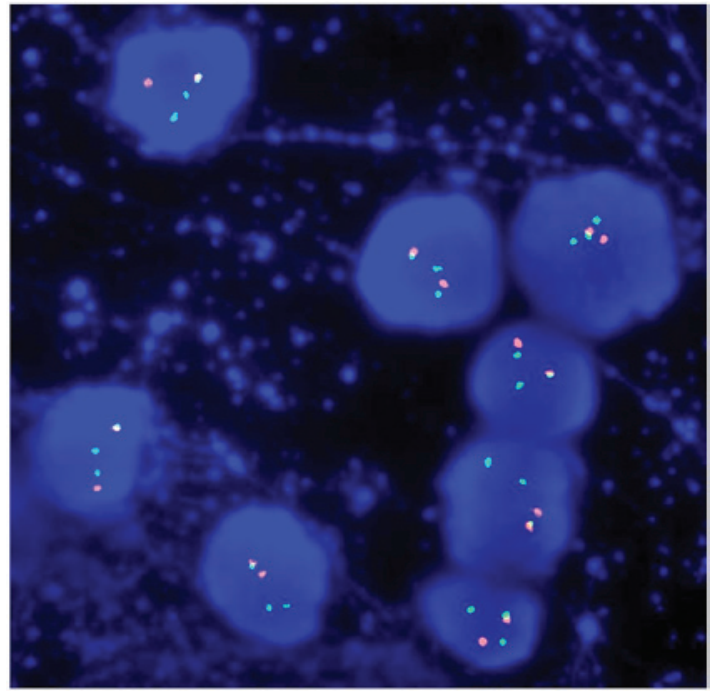

Figure 3. Following fluorescence in situ hybridization, t(11;14)(q13;q32) was positively detected in $80 \%$ of the bone marrow cells analyzed out of 200 cells (magnification, $\mathrm{x} 1,000)$.

(q13;q32) are positive for Cyclin D1 (3). A total of $66 \%$ of the PCM patients with $\mathrm{t}(11 ; 14)$ translocation express CD20 (4). This often leads to a misdiagnosis of lymphoplasmacytic lymphoma, mantle cell lymphoma or other B-cell lymphomas. MYD88 L265P somatic mutation is highly prevalent in lymphoplasmacytic lymphoma (5) and was not detected in the current case. It is important to corroborate the clinical and pathological findings with a multitude of tests, including flow cytometry, immunohistochemistry and mutation testing, and to obtain histological proof of any lymphadenopathy in a case of PCM with lymphoplasmacytoid morphology.

The prognosis of $\mathrm{t}(11 ; 14)$ translocation is also controversial. Moreau et al (6) suggested that PCM with $\mathrm{t}(11 ; 14)$ is associated with a superior overall survival compared with either $t(4 ; 14)$ or no translocation, however the study group were treated with older drug regimens (VAD). With novel agents, including lenalidomide, PCM with $\mathrm{t}(11 ; 14)$ is associated with inferior overall survival (7).

Anti-CD20 reagents, including rituximab, have not been demonstrated to be beneficial as singularly administered reagents in CD20-positive PCM (8). In a prospective phase II study of 14 patients, only one patient had a minor response. Disease progression, or lack of response to rituximab, was postulated to be due to the lack of B-cell involvement in continued propagation in PCM patients (9).

No large clinical trials have verified the benefits of combination therapy of rituximab and conventional agents in CD20-positive PCM. Bergua et al (10) reported a case of relapsed CD20-positive PCM which was heavily pretreated with chemotherapies, including bortezomib, and the relapse was responsive to rituximab, vincristine, adriamycin and dexamethasone. The toxicity of VAD, however, should not go unnoticed. In a prospective multicenter study of 139 PCM patients receiving VAD, 27\% developed an infection of $\mathrm{WHO}$ grade 2 or above, of which pulmonary infections were the most common (11). This observation could be attributed to the presence of a central line catheter and the high-dose steroid. Previously, use of venetoclax, a B cell lymphoma-2 inhibitor 
as a monotherapy, has demonstrated promising anti-myeloma activity in PCM with $\mathrm{t}(11 ; 14)$ translocation, with an acceptable safety profile (12).

In conclusion, the initial diagnosis of PCM with $\mathrm{t}(11 ; 14)$ may be difficult based on the morphology and flow cytometry. The treatment options and prognosis are also variable and further studies should be performed.

\section{Acknowledgements}

The authors would like to thank Dr Ma Shiu Kwan Edmond (Hong Kong Sanatorium and Hospital, Hong Kong, SAR, China) for his supervision.

\section{Funding}

No funding was received.

\section{Availability of data and materials}

Data sharing is not applicable as no datasets were generated or analyzed during the current study.

\section{Authors' contributions}

SYK, WKL and SFY interpreted laboratory data, reviewed slides, performed critical appraisal of the results and wrote the manuscript. SYK, KSL, KPY, CYH, HKL, HNC and YMY and SFY were involved in diagnostic workup procedures, treatment planning and decisions, patient care and critical appraisal of the manuscript. All authors gave final approval of the version to be published.

\section{Ethics approval and consent to participate}

Written informed consent was obtained the patient's father.

\section{Consent for publication}

Written informed consent was obtained the patient's father for the publication of any data and accompanying images.

\section{Competing interests}

The authors declare that they have no competing interests.

\section{References}

1. Chesi M and Bergsagel PL: Molecular pathogenesis of multiple myeloma: Basic and clinical updates. Int J Hematol 97: 313-323, 2013.

2. Fonseca R, Blood EA, Oken MM, Kyle RA, Dewald GW Bailey RJ, Van Wier SA, Henderson KJ, Hoyer JD, Harrington D, et al: Myeloma and the $\mathrm{t}(11 ; 14)(\mathrm{q} 13 ; \mathrm{q} 32)$; evidence for a biologically defined unique subset of patients. Blood 99: 3735-3741, 2002 .

3. Hoyer JD, Hanson CA, Fonseca R, Greipp PR, Dewald GW and Kurtin PJ: The $(11 ; 14)(\mathrm{q} 13 ; \mathrm{q} 32)$ translocation in multiple myeloma. A morphologic and immunohistochemical study. Am J Clin Pathol 113: 831-837, 2000.

4. Robillard N, Avet-Loiseau H, Garand R, Moreau P, Pineau D, Rapp MJ, Harousseau JL and Bataille R: CD20 is associated with a small mature plasma cell morphology and $t(11 ; 14)$ in multiple myeloma. Blood 102: 1070-1071, 2003.

5. Hamadeh F, MacNamara SP, Aguilera NS, Swerdlow SH and Cook JR: MYD88 L265P mutation analysis helps define nodal lymphoplasmacytic lymphoma. Mod Pathol 28: 564-574, 2015.

6. Moreau P, Facon T, Leleu X, Morineau N, Huyghe P, Harousseau JL, Bataille R and Avet-Loiseau H; Intergroupe Francophone du Myélome: Recurrent 14q32 translocations determine the prognosis of multiple myeloma, especially in patients receiving intensive chemotherapy. Blood 100: 1579-1583, 2002.

7. Kaufman GP, Gertz MA, Dispenzieri A, Lacy MQ, Buadi FK, Dingli D, Hayman SR, Kapoor P, Lust JA, Russell S, et al: Impact of cytogenetic classification on outcomes following early high-dose therapy in multiple myeloma. Leukemia 30: 633-639, 2016.

8. Moreau P, Voillat L, Benboukher L, Mathiot C, Dumontet C, Robillard N, Hérault O, Garnache F, Garand R, Varoqueaux N, et al; IFM group: Rituximab in CD20 positive multiple myeloma. Leukemia 21: 835-836, 2007.

9. Treon SP, Pilarski LM, Belch AR, Kelliher A, Preffer FI, Shima Y, Mitsiades CS, Mitsiades NS, Szczepek AJ, Ellman L, et al: CD20-directed serotherapy in patients with multiple myeloma: Biologic considerations and therapeutic applications. J Immunother 25: 72-81, 2002.

10. Bergua JM, Cabrera C, Arteta EG and Prieto J: Rituximab in CD20 positive multiple myeloma. Leukemia 22: 1082-1083, 2008.

11. Segeren CM, Sonneveld P, van der Holt B, Baars JW, Biesma DH, Cornellissen JJ, Croockewit AJ, Dekker AW, Fibbe WE, Löwenberg B, et al: Vincristine, doxorubicin and dexamethasone (VAD) administered as rapid intravenous infusion for first-line treatment in untreated multiple myeloma. Br J Haematol 105: 127-130, 1999.

12. Kumar S, Kaufman J, Gasparetto C, Mikhael J, Vij R, Pegourie B, et al: Efficacy of venetoclax as targeted therapy for relapsed/ refractory $\mathrm{t}(11 ; 14)$ multiple myeloma. Blood. 2017;:blood-201706-788786. 